\title{
Estimating the waste heat recovery in the European Union Industry
}

\author{
Giuseppe Bianchi $^{1} \cdot$ Gregoris P. Panayiotou $^{2} \cdot$ Lazaros Aresti $^{3}\left({ }^{1} \cdot\right.$ Soteris A. Kalogirou $^{2} \cdot$ \\ Georgios A. Florides $^{4} \cdot$ Kostantinos Tsamos $^{1} \cdot$ Savvas A. Tassou $^{1} \cdot$ Paul Christodoulides $^{4}$ (i) \\ ${ }^{1}$ Center for Sustainable Energy Use in Food Chains, Institute of Energy Futures, Brunel University London, Uxbridge, Middlesex UB8 3PH, UK \\ ${ }^{2}$ Department of Mechanical Engineering and Materials Science and Engineering, Cyprus University of Technology, 3603 Limassol, Cyprus \\ ${ }^{3}$ Department of Electrical Engineering, Computer Engineering and Informatics, Cyprus University of Technology, 3603 Limassol, Cyprus \\ ${ }^{4}$ Faculty of Engineering and Technology, Cyprus University of Technology, 3603 Limassol, Cyprus
}

Received: 18 April 2019/Revised: 2 August 2019/Accepted: 2 August 2019/Published online: 25 September 2019

(C) The Author(s) 2019. This article is published with open access at Springerlink.com

\begin{abstract}
Industrial processes are currently responsible for nearly $26 \%$ of European primary energy consumptions and are characterized by a multitude of energy losses. Among them, the ones that occur as heat streams rejected to the environment in the form of exhausts or effluents take place at different temperature levels. The reduction or recovery of such types of energy flows will undoubtedly contribute to the achievement of improved environmental performance as well as to reduce the overall manufacturing costs of goods. In this scenario, the current work aims at outlining the prospects of potential for industrial waste heat recovery in the European Union (EU) upon identification and quantification of primary energy consumptions among the major industrial sectors and their related waste streams and temperature levels. The paper introduces a new approach toward estimating the waste heat recovery in the European Union industry, using the Carnot efficiency in relation to the temperature levels of the processes involved. The assessment is carried out using EU statistical energy databases. The overall EU thermal energy waste is quantified at $920 \mathrm{TWh}$ theoretical potential and $279 \mathrm{TWh}$ Carnot potential.
\end{abstract}

Keywords Waste heat recovery - WHR potential estimation - Carnot potential - WHR Europe - Energy statistics $\cdot$ Energy recovery $\cdot$ Heat to power conversion

Paul Christodoulides

paul.christodoulides@cut.ac.cy

\section{Introduction}

The European Union (EU), with twenty-eight (28) member states, over 4 million $\mathrm{km}^{2}$ and over 512 million inhabitants, is currently responsible for about $12 \%$ of the world final energy consumptions (1122 Mtoe in 2017) and for about $11 \%$ of the world final $\mathrm{CO}_{2}$ emissions (8.7 greenhouse gas emissions tonnes per capita in 2016) (European C 2016a, b; International Energy Agency 2016). Industry in the EU accounts for about $26 \%$ of the final energy consumption and for about $48 \%$ of the final $\mathrm{CO}_{2}$ emissions (European $\mathrm{C}$ 2016b). EU, being at the forefront of awareness and involvement in global environmental issues, has contributed in the reduction of greenhouse gas emissions by about $23 \%$ compared to the ones in 1990 . One of the key EU-related targets for 2030 is to reach a reduction of at least $40 \%$ with respect to the same reference year (European C 2016a), through energy savings and a more intensive usage of renewable energy sources.

To this end, recovery actions from existing energetic systems can offer substantial primary energy savings with simultaneous equally important greenhouse gas emission reductions. One such example is the industrial processes that are characterized by a multitude of waste heat streams at different temperature levels. In this context, the process of waste heat recovery (WHR) is the capturing of heat from such waste streams and its direct utilization, through its upgrading into a more useful temperature and/or its conversion into electrical power or cooling. The energy generated from heat recovery can either be used for the needs of the same industrial site or exported to neighboring facilities or to electrical or heat distribution networks.

Through the rising concerns over the cost of energy and energy security as well as general environmental and 
sustainability considerations, there is nowadays increased global interest in the development and application of WHR systems, motivated even by government regulatory requirements on emissions reduction targets. The Global WHR market is expected to surpass $\$ 65$ billion by the end of 2021 with a compound annual growth rate (CAGR) of 6.9\% (Markets 2018). Newer report suggests a compound annual growth rate of $4.8 \%$ by the end of 2025 (QYResearch G 2018). Europe leads the market related to WHR equipment with a $38 \%$ share of the global market as of 2012 (Markets 2018).

The Asia-Pacific region has been experiencing the highest growth rate in the last few years, of about $10 \%$ per annum, with China and India accounting for the highest number of installations of heat recovery units. For these figures to insist and expand in the future, however, and for the European manufacturing and user industry to benefit from these developments, technological improvements and innovations should take place aimed at improving the energy efficiency of heat recovery equipment and reducing installed costs [see, for example, Agathokleous et al. (2019) and Jouhara et al.(2018)].

Depending on their nature, waste heat streams may be valued through different approaches. For instance, highpressure effluents are suitable for direct expansion, while low-temperature flue gases can be exploited through condensing economizers that aim at recovering the latent heat of the water vapors. Other WHR techniques include the mechanical or thermal recompression of vapors as well as the usage of industrial heat pumps (Ommen et al. 2015). Some energy systems, for example the internal combustion engines for road transportation or power generation, are suitable for novel technologies such as the six-stroke internal combustion engine cycle or the thermoelectric generators that perform a conversion of heat into direct current electricity without involving any additional equipment (Yang et al. 2019; Merienne et al. 2019).

In industrial scenarios, the most common WHR approaches are the ones based on sensible preheating as well as the waste heat to power generation via bottoming thermodynamic cycles. In the first case, heat exchangers and heat transfer fluids are employed to recover the energy from the waste heat source and either to import it back to the same industrial process or to export it over the fence, i.e., in near industrial sites or in residential areas for domestic heating. In the latter, the working fluid that performs an enthalpy gain during the heat recovery process undergoes a series of thermodynamic transformations that produce a net positive power output. Unlike heat recovery, which requires a heat demand in the industrial site or in the nearby ones, an electrical energy recovery is undoubtedly more favorable in terms of energy management since the surplus of electricity due to the recovery process can interact with the electrical grid and its larger capacity. Furthermore, the nobler nature of electric energy implies greater economic and emission savings. For instance, if the recovery occurred via thermal form as if it was resulting from a combustion of natural gas, 1 MWh of thermal energy recovered would avoid 0.202 tons of $\mathrm{CO}_{2}$ emitted in the atmosphere, while the same energy recovery but in electrical form would have an emission factor of $0.460 \mathrm{tCO}_{2} / \mathrm{MWhe}$ (Markets 2018). On the other hand, conversion efficiencies of heat to power approaches are lower than the ones that characterize heat recovery devices. The reference cycles for these energy recovery technologies have been extensively investigated by the scientific and industrial communities. In particular, plenty of research has been performed on organic Rankine cycles (ORC) using pure fluids or zeotropic mixtures as well as different machinery and heat transfer equipments (Liu et al. 2004; Wei et al. 2007; Li et al. 2014).

A comprehensive review of the convectional WHR technologies was introduced by Jouhara et al. (2018), where various technologies were discussed, such as recuperators, regenerators, furnace regenerators and rotary regenerators or heat wheels, passive air preheaters, regenerative and recuperative burners, plate heat exchangers, economizers, as well as units of waste heat boilers and runaround coil (RAC). Among the available technologies, thermal energy storage (TES) (in particular when using phase change materials) offers the possibility of solving the problem of matching the discontinuous waste heat supply with the heat demand and achieving a better capacity factor (Miró et al. 2016; Elias and Stathopoulos 2019). In addition to the convectional WHR approaches, new technologies have been proposed by Agathokleous et al. (2019), including trilateral flash cycle, Joule-Brayton cycle working with supercritical carbon dioxide, flat heat pipes and condensing economizer for acidic effluents.

The main aim of the current paper is to present the industrial WHR potential available in the member states of the European Union. In Sect. 2, the calculation methodology is introduced. It is based on the use of the Carnot efficiency through the identification of the WHR processes in different temperature levels. An assessment of the WHR potential in EU industry is given in Sect. 3, where results are detailed by temperature levels, country and industrial sectors. We conclude in Sect. 4 with suggestions for future work.

\section{Methodology}

Several studies have addressed the estimation of waste heat potential as well as the environmental effect. For example, Papapetrou et al. (2018) have proposed a new methodology on estimating the WHR potential, presenting results as per temperature level and per industrial sector for the EU 
region. The authors have exploited results from 425 UK industrial sites in the years 2000-2003 to calculate the waste heat fractions, where they then adjusted the waste heat fraction for the EU countries and consequently alternating for the year 2015. The estimation of the technical WHR potential in the UK industry was also described by Hammond and Norman (2014). Emphasis has been given on that the savings estimation with technical potential will be lower than the maximum theoretical potential, but also higher than the economic potential. Forman et al. (2016) have presented a novel-at the time-approach for the estimation of the global WHR potential through the calculation of the Carnot potential. The approach above was used to estimate the waste heat emissions from the power generation industry, transport industry and construction industry on a global scale. The authors have gone a step further to investigate the environmental impact with potential savings on the emissions by using the WHR theoretical potential.

When different technologies are considered for using the industrial energy yielding within the WHR potential, it is essential to distinguish which type of potential is considered (Brueckner et al. 2014), namely the theoretical (or physical) potential (IPCC 2007), the technical potential or the economic feasible potential (Roth et al. 1996) (Fig. 1a). The theoretical potential considers physical constraints only, such as the heat having to be above ambient temperature, bound in a medium and so on. Note that, in this frame, it is not considered if it is possible to extract the heat from the carrier fluid, or whether it is possible to use it.

The constraints above establish the technical potential, which naturally depends on the technologies considered. An important technical constraint is the required minimum temperature. The technical potential to use waste heat is ruled by two key constraints: the boundary conditions of the technology itself and a heating or cooling demand that is necessary.

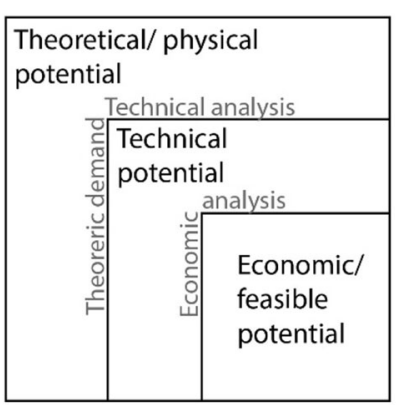

a

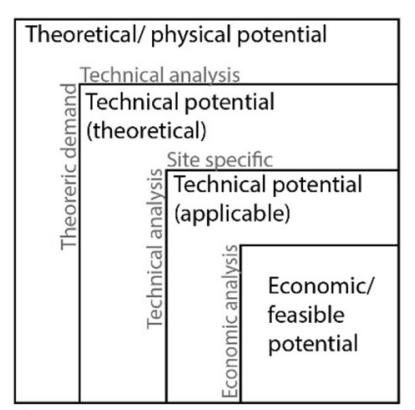

b
Fig. 1 Types of WHR potential: a graph adapted from Forman et al. (2016), Brueckner et al. (2014) and IPCC (2007) b proposed modified graph
In the present work, going a step further, the technical potential is separated into technical potential (theoretical) and technical potential (applicable). These are distinguishable through the fact that the former can be calculated using a theoretical/generic process-related analysis, while the latter can be calculated using onsite data with all plant specific parameters taken into consideration (see proposed Fig. 1b). Accordingly, the feasibility of the technology considered can be eventually analyzed by means of economic criteria.

In the current study, the theoretical WHR potential (simply referred to as theoretical potential from this point onward) has been estimated through the methodology proposed by Forman et al. (2016), applied to the energy statistics (reference year 2014) for the European Union. According to the classification made by Brueckner et al. (2014), on what concerns the data collection and the application of input parameters, Forman's methodology is a top-down approach, while on what concerns the usage of literature data, coefficients and estimation, the calculation method used is of medium accuracy.

Figure 2 shows a given energy system (industrial sector as well as a specific site) being characterized by primary energy consumptions that result from a mixture of several primary energy sources (solid, liquid and gaseous fuels, as well as electricity and heat). Each of these energy inputs is not entirely converted into useful energy for the system but presents some loss terms that depend on the type of process. Moreover, not all the energy losses are accounted for the WHR potential estimation but only the ones related to
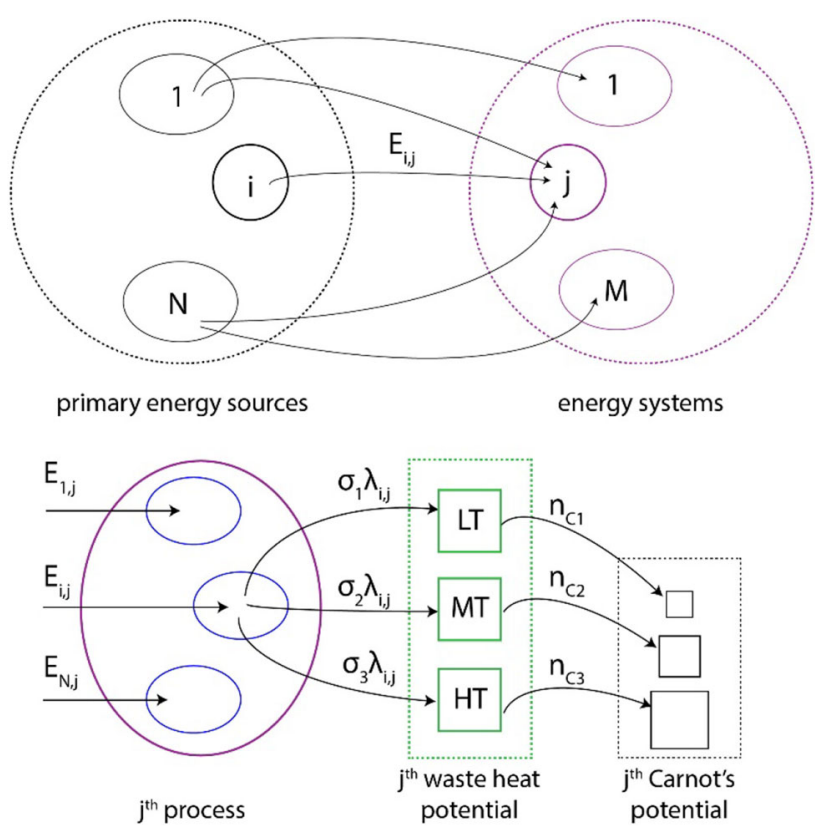

Fig. 2 Calculation methodology for WHR potential estimation 
exhausts (flue gas, vapor) and effluents (cooling water or air), which are concentrated waste heat streams and can be directly transferred. Other losses, such as radiation, electrical transmission and friction, are not taken into consideration due to, in general, low availability (Forman et al. 2016).

Within these assumptions, the theoretical WHR potential can be calculated according to the following equation,

$\mathrm{WHRP}=\sum_{i=1}^{N} \sum_{j=1}^{M} \lambda_{i j} E_{i j}$

where $E_{i j}$ represents the primary energy consumptions of a given source of the process and $\lambda_{i j}$ the percentage of primary energy that is converted into accountable waste heat losses (exhausts and effluents), with subscripts $i, j$ being explained in Fig. 2.

A further breakdown of the WHR potential can be performed with reference to the temperature levels that are commonly categorized into (Forman et al. 2016): low temperatures (LT): $<100{ }^{\circ} \mathrm{C}$, medium temperatures (MT): 100-300 ${ }^{\circ} \mathrm{C}$, high temperatures (HT): $>300{ }^{\circ} \mathrm{C}$. This way, Eq. (1) above can be detailed into the following equation,

$\mathrm{WHRP}=\sum_{i=1}^{N} \sum_{j=1}^{M} \sum_{k=1}^{3} \sigma_{i j k} \lambda_{i j} E_{i j}$

incorporating weights $\sigma_{i j k}$ with sum equal to 1 and $k$-subscript refers to the temperature levels ( 1 for LT, 2 for MT and 3 for HT).

The database for the primary energy consumptions can be found in Panayiotou et al. (2017), while both loss and temperature-level coefficients can be found in Brueckner et al. (2014). Note that, when multiple loss coefficients were listed for the same primary energy source, the parameter used in the estimations was the weighted average of the listed ones.

In the context of thermodynamics, energy can be defined as the sum of exergy and anergy, where exergy stands for the energy that can be totally turned into technical work, while anergy is the destroyed exergy. Thus, the exergy content of waste/rejected heat can be calculated by the Carnot's theorem, which states that the maximum efficiency of a heat engine is determined by the two available heat reservoirs. Applying the Carnot efficiency, $\eta_{\mathrm{C}}$, to the waste heat amounts and their corresponding waste heat temperatures $\left(T_{\mathrm{c}}=298.15 \mathrm{~K}\right.$ of the cold reservoir and $T_{\mathrm{h}}$ of the hot reservoir) gives the respective, more realistic, technical WHR potential further indicated as Carnot potential:

$\mathrm{CWHRP}=\mathrm{WHRP} \times \eta_{\mathrm{C}}=\mathrm{WHRP} \times\left(1-\frac{T_{\mathrm{c}}}{T_{\mathrm{h}}}\right)$
The use of WHRP in Eq. (2) in Eq. (3) improves the accuracy of the calculations, giving more reliable values for both the theoretical WHRP and the Carnot WHRP, as these are presented in Sect. 3 below.

\subsection{Identification of the processes with WHR potential in each industrial sector}

Identification of the WHR processes is the key parameter to evaluate the potential of WHR based on the methodology described above. A previous research on the available processes and temperatures has been presented by Panayiotou et al. (2017). Therein, information of the available processes that implicate waste heat in the process is outlined by industry. There are 18 industries where WHR can be achieved, namely (1) the iron and steel industry, (2) the large combustion plants, (3) large volume inorganic chemicals: ammonia, acids and fertilizers, (4) large volume inorganic chemicals: solids and others industry, (5) food and tobacco, (6) production of glass, (7) production of organic fine chemicals, (8) production of nonferrous metals, (9) production of cement, lime and magnesium oxide, (10) production of polymers, (11) ferrous metals processing, (12) production of pulp, paper and board, (13) surface treatment using organic solvents, (14) tanning of hides and skins, (15) textiles industry, (16) waste incineration, (17) waste treatment and (18) wood-based panel production.

The main processes and their temperature levels (important for coefficient $\sigma_{i j k}$ in Eq. (2) above) that implicate waste heat in each of the industries above are summarized in Table 1 of the "Appendix."

Although identification of the processes for WHR exists in the literature, it is not straightforward within the manufacturing facilities to isolate the most suitable waste heat sources and processes. To overcome this issue and standardize the procedure, Simeone et al. (2016) have presented a decision support tool for the WHR options based on a framework (Woolley et al. 2018) that consists of four stages: waste heat survey, waste heat assessment, technology selection and decision support.

\section{Calculation of the waste heat recovery potential}

Based on the methodology described in Sect. 2, the calculations of the WHR potential per EU member state and per industrial sector are performed. 

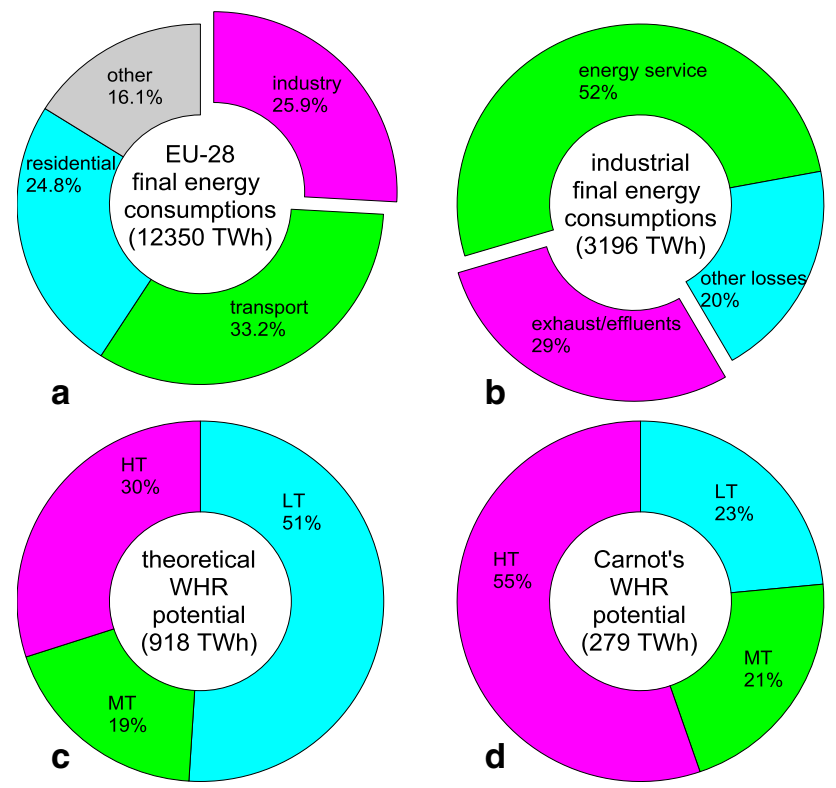

Fig. 3 Theoretical and Carnot WHR potentials in EU industry detailed by temperature levels

\subsection{Aggregated waste heat recovery potentials and EU member states}

The theoretical and Carnot potentials in the EU industry detailed by temperature levels are illustrated in Fig. 3. Industry accounts for almost the $26 \%$ of the overall primary energy consumptions (Fig. 3a). Nearly half of this energy is not spent on energy services (e.g., motion, heat, cooling, light and sound) but dissipated to the environment (Fig. 3b). Specifically, the waste energy through effluents or exhaust is the $29 \%$ of the industrial consumptions and it is equal to nearly $920 \mathrm{TWh}$. Other losses refer to energy waste that is not accountable for the current methodology. As reported in Fig. 3c, the greatest share of the energy waste occurs at LTs, i.e., temperatures lower than $100^{\circ} \mathrm{C}$. Nevertheless, waste heat at LT level has a significantly smaller share within the Carnot potential (23\% rather than $51 \%$ ) (Fig. 3d). Thus, the Carnot potential can offer a more specific indication on whether waste heat could still be used for technical work or, preferably, for heat transfer.

In overall terms in EU, industrial theoretical WHR potential accounts for nearly $920 \mathrm{TWh}$, while the Carnot WHR potential has been estimated at $279 \mathrm{TWh}$. As shown in Fig. 4, Germany owns more than $20 \%$ of the overall potential, while Italy, France and UK are the second most relevant countries with a share for each close to $10 \%$. Scandinavian or small member states as well as developing economies play a secondary role in the contribution to the whole WHR potential. Supplementary data in the

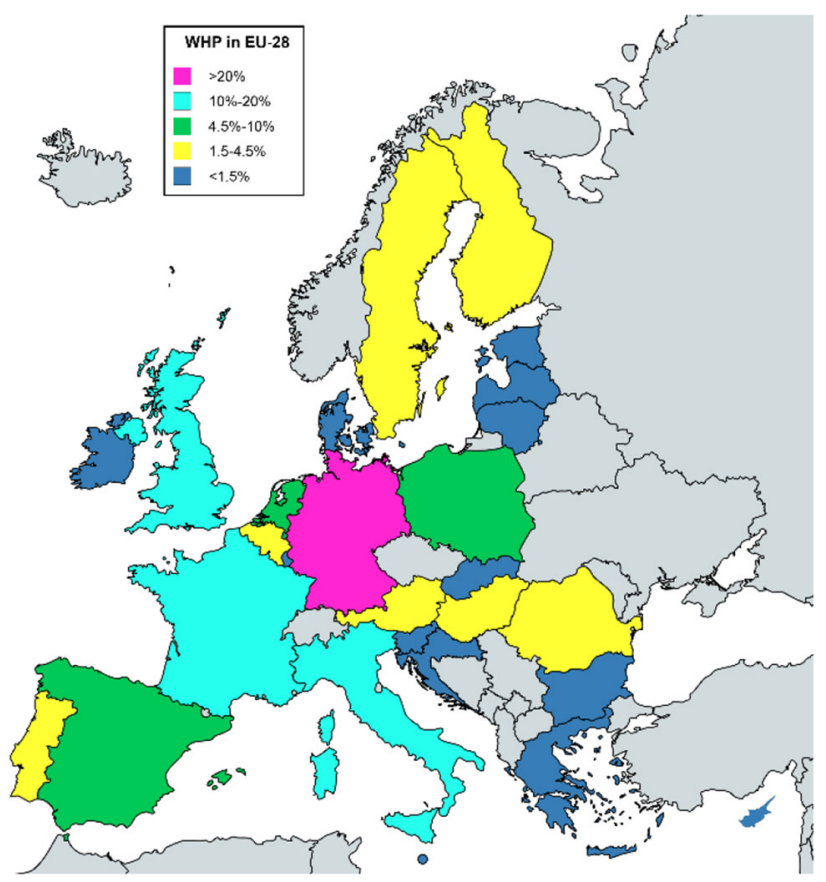

Fig. 4 Shares of WHR potential in the EU Industry by member state (total value: $920 \mathrm{TWh}$; theoretical: $279 \mathrm{TWh}-\mathrm{Carnot}$ )

"Appendix" (Tables 2, 3) report a breakdown of current energy consumptions as well as absolute values for theoretical and Carnot potentials in the EU industry divided by member state and industrial sector (see sequel).

\subsection{Detailed waste heat recovery potentials per industrial sector}

Recent statistics reported in Fig. 5 show that the industrial sectors that mostly contribute to the overall primary energy consumptions are the chemical and petrochemical (C\&P) as well as the iron and steel (I\&S) (Panayiotou et al. 2017). In these areas, the heat losses, as exhausts and effluents, assume maximum values in absolute as well as relative terms. In particular (Fig. 6a), the theoretical WHR potential in C\&P has been calculated to account for $25.9 \%$ of primary energy consumptions as opposed to $25.0 \%$ in I\&S. On the other hand, WHR potential in sectors like mining and quarrying as well as textile and leather is only $1.9 \%$ and $3.0 \%$, respectively. Except for nonferrous metals (e.g., aluminum industry) and nonmetallic minerals (which includes the cement industry), most of the theoretical WHR potential occurs at low temperature, as shown in Fig. 6 b.

When the Carnot efficiency is introduced to refine the actual potentials of the different sectors, several differences can be noticed in Fig. 7. The most significant one is the distribution of the useable temperature levels between the theoretical and the Carnot potential. This, being a very 
Fig. 5 Primary energy consumptions in EU industry (total value $12,350 \mathrm{TWh}$ )

(EuroStat 2018)

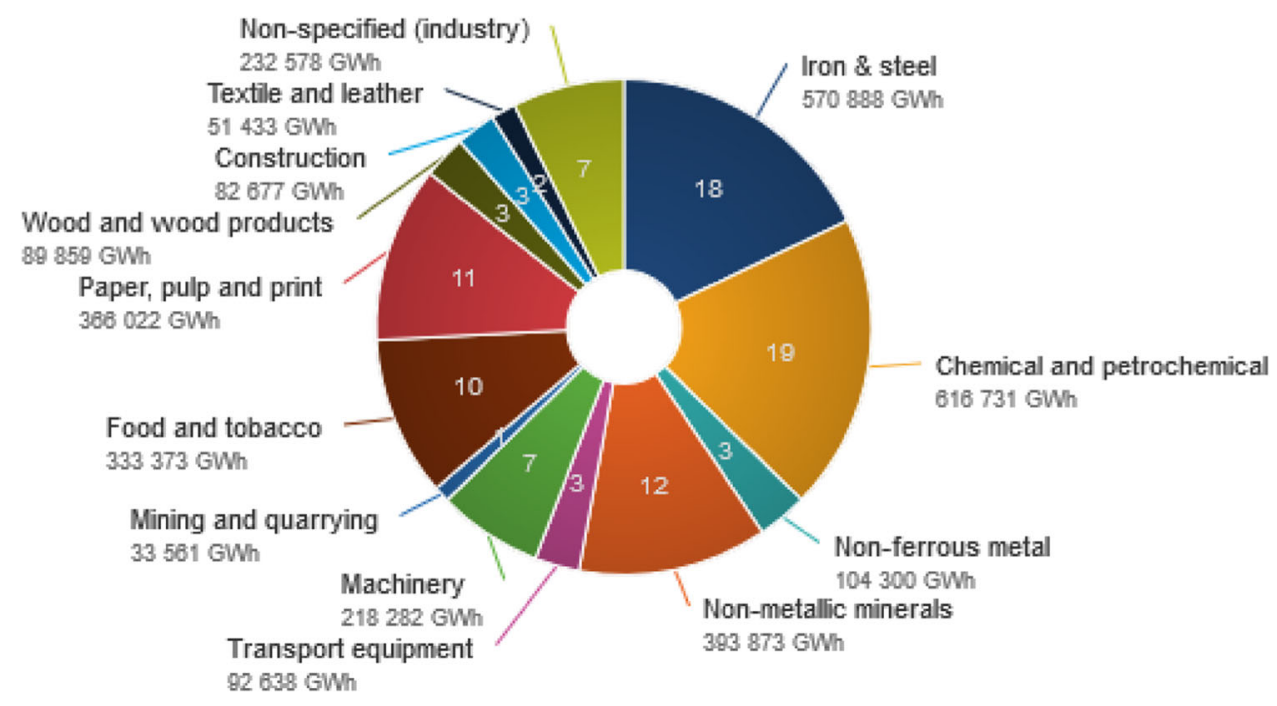

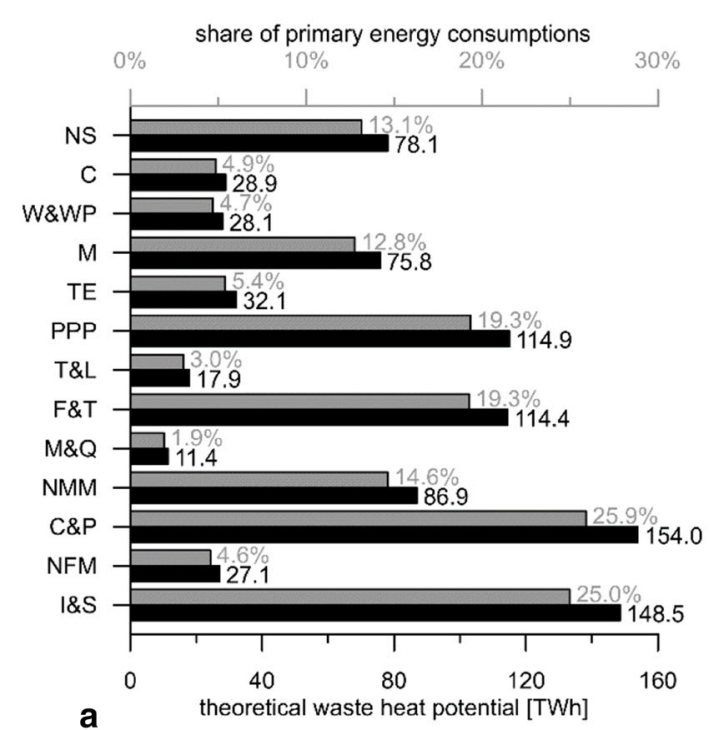

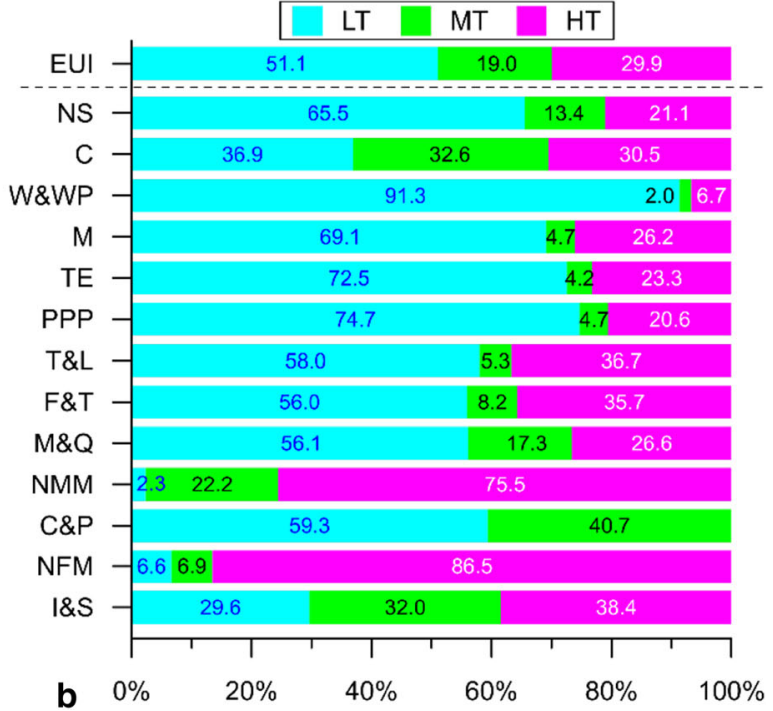

Fig. 6 a Theoretical WHR potential and relevance on primary energy consumptions for the EU industry, b breakdown of the theoretical WHR potential in the EU industry with respect to temperature levels

important novel ingredient of the current methodology, affects the calculation of the Carnot potential as the WHR technologies' coefficient of performance (COP) depends on temperature levels. Specifically, since most of the available heat in C\&P occurs at LT and MT levels, the actual potential in this sector leaves the leading position toward the I\&S, whose potential accounts for 54.3 TWh. Other promising industrial sectors are the nonmetallic minerals as well as the food and tobacco ones, where the Carnot WHR potential is equal to $43.8 \mathrm{TWh}$ and $35.1 \mathrm{TWh}$, respectively.

The results above indicate the difference of the theoretical and the Carnot potential, with the temperature levels being accountable. These results, based on the newly presented Eq. (2) above, constitute a significant improvement on the accuracy of calculations, compared to previous studies [see, e.g., Forman et al. (2016) and Panayiotou et al. (2017)].

\section{Conclusions}

In the current study, the WHR potential of the EU industry has been "revisited" through a more elegant methodology that takes into consideration the temperature levels of the 

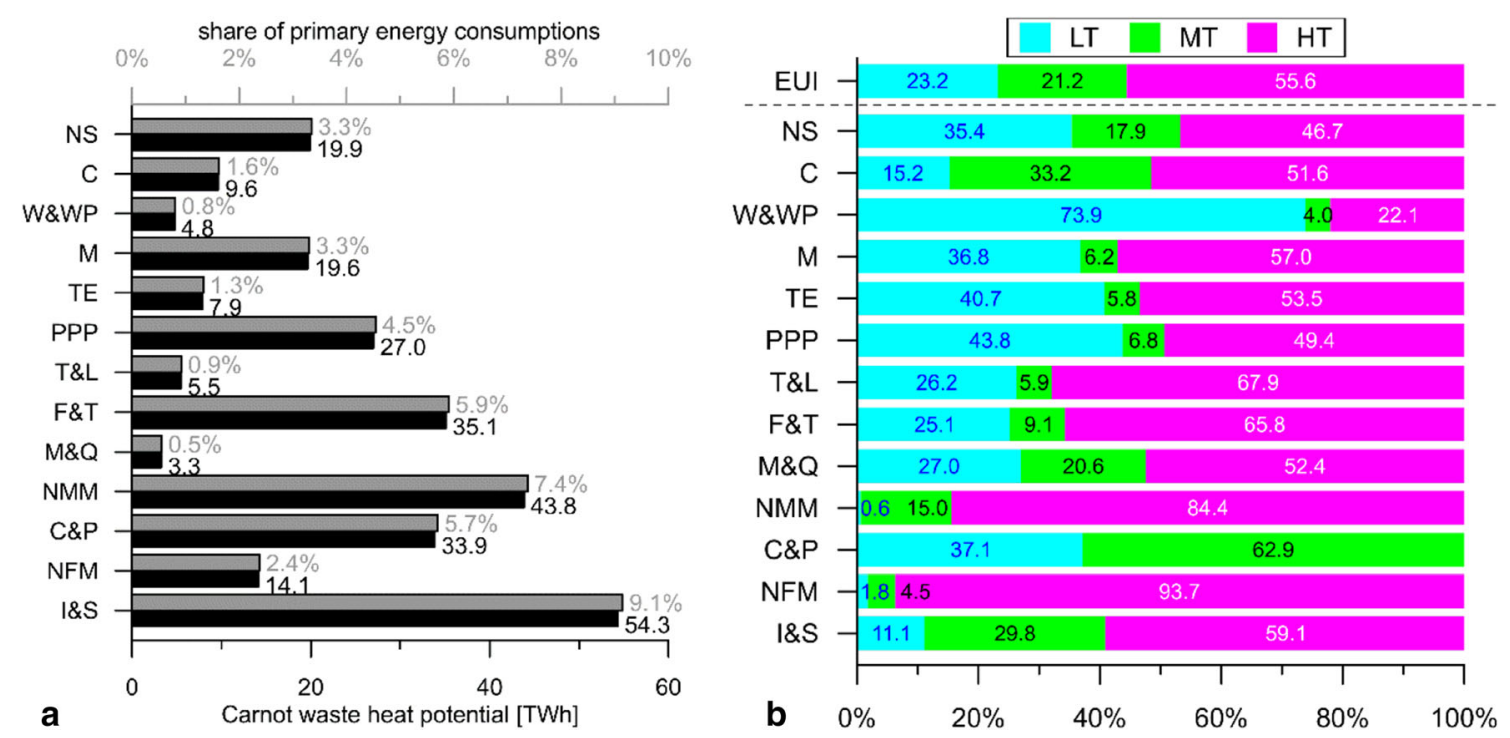

Fig. 7 a Carnot WHR potential and relevance on primary energy consumptions for the EU industry, b breakdown of the Carnot WHR potential in the EU industry with respect to temperature levels

process. Both the theoretical potential and the Carnot potential have been addressed. Results have been given for EU countries as well as EU industries. These verify that the potential is high, of the order of $300 \mathrm{TWh} /$ year, even for the conservative estimation used here (as opposed to the less accurate (Panayiotou et al. 2017), less detailed (Forman et al. 2016) or less conservative methods (Papapetrou et al. 2018) used).

With insight information into the different processes, together with their temperature ranges, used in all industrial sectors in the EU having been identified [see Agathokleous et al. (2019), Jouhara et al. (2018), Papapetrou et al. (2018) and Panayiotou et al. (2017)], the next step is to assess the potential market of the most intensive industrial sectors in relation to old and "new" technologies and their COPs and how to improve recovery techniques (Agathokleous et al. 2019). It is also important to obtain further knowledge on barriers (e.g., financial, technological, legislative) to the adoption of WHR technologies and see how these can be overcome.
Acknowledgements The research presented in this paper has received funding from: (1) the European Union's Horizon 2020 research and innovation program under Grant agreement No. 680599 , (2) Innovate UK (Project No. 61995-431253, (3) Engineering and Physical Sciences Research Council UK (EPSRC), Grant No. EP/ P510294/1; (4) Research Councils UK (RCUK), Grant No. EP/ K011820/1. The authors would like to acknowledge the financial support from these organizations as well as contributions from industry partners: Spirax Sarco Engineering PLC, Howden Compressors Ltd, Tata Steel, Arctic Circle Ltd, Cooper Tires Ltd and Industrial Power Units Ltd.

Open Access This article is distributed under the terms of the Creative Commons Attribution 4.0 International License (http://crea tivecommons.org/licenses/by/4.0/), which permits unrestricted use, distribution, and reproduction in any medium, provided you give appropriate credit to the original author(s) and the source, provide a link to the Creative Commons license, and indicate if changes were made.

\section{Appendix}

See Tables 1, 2 and 3. 
Table 1 Main processes and their temperature levels per industrial sector

\begin{tabular}{|c|c|c|c|}
\hline Industry/temperature level of process & LT & MT & HT \\
\hline Iron and steel & - & - & $\begin{array}{l}\text { Blast furnace/basic oxygen } \\
\text { furnace route } \\
\text { Direct melting of scrap (electric } \\
\text { arc furnace) } \\
\text { Direct reduction } \\
\text { Smelting reduction }\end{array}$ \\
\hline Large combustion plants & $\begin{array}{l}\text { Cogeneration/combined heat } \\
\text { and power }\end{array}$ & Steam generation & $\begin{array}{l}\text { Combined cycle plants } \\
\text { Gasification/liquefaction } \\
\text { General fuel heat conversion } \\
\text { Steam generation }\end{array}$ \\
\hline $\begin{array}{l}\text { Large volume inorganic chemicals: } \\
\text { ammonia, acids and fertilizers }\end{array}$ & - & - & $\begin{array}{l}\text { Conventional steam reforming } \\
\text { Sulfuric acid process }\end{array}$ \\
\hline $\begin{array}{l}\text { Large volume inorganic chemicals: solids } \\
\text { and others }\end{array}$ & - & Sulfur burning & $\begin{array}{l}\text { Sodium silicate plant } \\
\text { Tank furnace process }\end{array}$ \\
\hline Food and tobacco & $\begin{array}{l}\text { Crude vegetable oil production } \\
\text { from oilseeds } \\
\text { Heat recovery from cooling } \\
\text { systems }\end{array}$ & $\begin{array}{l}\text { Solubilization/alkalizing } \\
\text { Utility processes }\end{array}$ & High-temperature frying \\
\hline Glass & - & - & $\begin{array}{l}\text { Heating the furnaces primary } \\
\text { melting }\end{array}$ \\
\hline Organic fine chemicals & Processes of energy supply & - & $\begin{array}{l}\text { Co-incineration of liquid waste } \\
\text { Thermal oxidation of VOCs }\end{array}$ \\
\hline Nonferrous metals & - & $\begin{array}{l}\text { Primary lead and secondary } \\
\text { lead production }\end{array}$ & $\begin{array}{l}\text { Smelting } \\
\text { Zinc sulfide (sphalerite) }\end{array}$ \\
\hline Cement, lime and magnesium oxide & - & - & $\begin{array}{l}\text { Clinker burning } \\
\text { Kiln firing }\end{array}$ \\
\hline Polymers & $\begin{array}{l}\text { Thermal treatment of waste } \\
\text { water }\end{array}$ & - & - \\
\hline Ferrous metals processing & - & - & Hot rolling mill \\
\hline Pulp, paper and board & $\begin{array}{l}\text { Chemical pulping } \\
\text { Mechanical and chemi- } \\
\text { mechanical pulping } \\
\text { Papermaking and related } \\
\text { processes }\end{array}$ & $\begin{array}{l}\text { Chemical pulping } \\
\text { Mechanical and chemi- } \\
\text { mechanical pulping }\end{array}$ & Chemical pulping \\
\hline Surface treatment using organic solvents & Manufacturing of abrasives & Coil coating & $\begin{array}{l}\text { Drying and curing } \\
\text { Manufacturing of abrasives } \\
\text { Printing } \\
\text { Waste gas treatment from } \\
\text { enameling }\end{array}$ \\
\hline Tanning of hides and skins & Drying & - & - \\
\hline Textiles industry & $\begin{array}{l}\text { Dyeing } \\
\text { Optimization of cotton warp } \\
\text { yarn }\end{array}$ & $\begin{array}{l}\text { Drying } \\
\text { Optimization of cotton warp } \\
\text { yarn }\end{array}$ & $\begin{array}{l}\text { Dirt removal } \\
\text { Oxidation }\end{array}$ \\
\hline Waste incineration & - & $\begin{array}{l}\text { Drying and degassing } \\
\text { Pyrolysis }\end{array}$ & $\begin{array}{l}\text { Combustion } \\
\text { Gasification } \\
\text { Oxidation } \\
\text { Pyrolysis }\end{array}$ \\
\hline
\end{tabular}


Table 1 continued

\begin{tabular}{llll}
\hline Industry/temperature level of process & LT & MT & HT \\
\hline Waste treatment & Drying & Catalytic combustion & Catalytic combustion \\
& & Dyeing of wood particles & $\begin{array}{l}\text { Dyeing of wood particles } \\
\text { Incineration regeneration of carbon thermal treatment }\end{array}$ \\
Wood-based panel production & - & $\begin{array}{l}\text { Drying of wood fibers } \\
\text { Lamination } \\
\text { Pressing }\end{array}$ & - \\
\hline
\end{tabular}

Table 2 Breakdown of theoretical waste heat potential divided by member state and industrial sector [TWh]

\begin{tabular}{|c|c|c|c|c|c|c|c|c|c|c|c|c|c|c|}
\hline & $I \& S$ & NFM & $\mathrm{C} \& \mathrm{P}$ & NMM & M\&Q & $\mathrm{F} \& \mathrm{~T}$ & $\mathrm{~T} \& \mathrm{~L}$ & PPP & $\mathrm{TE}$ & M & W\&WP & $\mathrm{C}$ & NS & Total \\
\hline $\mathrm{AU}$ & 7.3 & 0.8 & 2.7 & 1.9 & 0.6 & 2.2 & 0.3 & 6.1 & 0.5 & 2.5 & 2.4 & 2.1 & 0.8 & 30.3 \\
\hline $\mathrm{BE}$ & 6.8 & 0.8 & 12.3 & 3.4 & 0.1 & 5.4 & 0.7 & 2.5 & 1.0 & 0.8 & 0.7 & 0.7 & 2.0 & 37.4 \\
\hline BG & 0.3 & 0.4 & 2.6 & 1.4 & 0.3 & 1.0 & 0.3 & 0.7 & 0.1 & 0.5 & 0.2 & 0.3 & 0.6 & 8.6 \\
\hline $\mathrm{CR}$ & 0.1 & 0.1 & 0.4 & 0.9 & 0.1 & 0.9 & 0.1 & 0.2 & 0.0 & 0.3 & 0.1 & 0.5 & 0.2 & 3.8 \\
\hline $\mathrm{CY}$ & 0.0 & 0.0 & 0.0 & 0.5 & 0.0 & 0.1 & 0.0 & 0.0 & 0.0 & 0.0 & 0.0 & 0.0 & 0.0 & 0.7 \\
\hline $\mathrm{CZ}$ & 5.9 & 0.3 & 3.1 & 2.7 & 0.3 & 2.3 & 0.5 & 2.1 & 1.6 & 2.8 & 0.8 & 0.7 & 2.3 & 25.4 \\
\hline DK & 0.2 & 0.0 & 0.7 & 1.2 & 0.2 & 2.3 & 0.1 & 0.3 & 0.1 & 0.9 & 0.2 & 0.7 & 0.4 & 7.3 \\
\hline $\mathrm{EE}$ & 0.0 & 0.0 & 0.1 & 0.4 & 0.1 & 0.3 & 0.1 & 0.2 & 0.0 & 0.2 & 0.4 & 0.2 & 0.1 & 2.0 \\
\hline FI & 3.4 & 0.4 & 3.4 & 0.7 & 0.7 & 1.6 & 0.2 & 20.9 & 0.2 & 1.3 & 2.0 & 1.8 & 0.8 & 37.5 \\
\hline FR & 17.5 & 2.5 & 12.5 & 9.2 & 0.8 & 17.8 & 1.1 & 8.8 & 3.6 & 6.3 & 2.7 & 4.5 & 2.9 & 90.2 \\
\hline $\mathrm{DE}$ & 39.3 & 6.0 & 41.6 & 16.1 & 1.3 & 20.2 & 1.9 & 21.7 & 11.7 & 23.2 & 6.4 & 0.0 & 9.3 & 198.8 \\
\hline GR & 0.4 & 3.0 & 0.5 & 2.1 & 0.4 & 2.2 & 0.1 & 0.4 & 0.1 & 0.2 & 0.1 & 0.7 & 0.9 & 11.0 \\
\hline $\mathrm{HU}$ & 1.4 & 0.6 & 3.7 & 1.1 & 0.1 & 2.3 & 0.2 & 0.7 & 0.8 & 1.6 & 0.2 & 0.9 & 0.9 & 14.4 \\
\hline IE & 0.0 & 2.9 & 0.7 & 1.0 & 0.5 & 1.8 & 0.1 & 0.1 & 0.1 & 1.0 & 0.5 & 0.0 & 0.7 & 9.2 \\
\hline IT & 14.2 & 3.0 & 11.7 & 11.8 & 0.5 & 11.2 & 4.6 & 8.8 & 1.5 & 13.5 & 1.4 & 1.4 & 5.2 & 88.9 \\
\hline LV & 0.0 & 0.0 & 0.1 & 0.4 & 0.0 & 0.4 & 0.0 & 0.0 & 0.0 & 0.1 & 1.5 & 0.2 & 0.0 & 2.7 \\
\hline LT & 0.0 & 0.0 & 1.2 & 0.5 & 0.0 & 0.8 & 0.1 & 0.1 & 0.0 & 0.1 & 0.3 & 0.2 & 0.2 & 3.4 \\
\hline LU & 0.7 & 0.0 & 0.2 & 0.3 & 0.0 & 0.1 & 0.1 & 0.0 & 0.0 & 0.0 & 0.1 & 0.1 & 0.1 & 1.8 \\
\hline MT & 0.0 & 0.0 & 0.0 & 0.0 & 0.0 & 0.0 & 0.0 & 0.0 & 0.0 & 0.0 & 0.0 & 0.0 & 0.1 & 0.2 \\
\hline NL & 7.1 & 0.4 & 22.0 & 1.4 & 0.4 & 8.0 & 0.4 & 2.3 & 0.4 & 2.0 & 0.2 & 2.7 & 1.3 & 48.7 \\
\hline PL & 7.6 & 1.6 & 7.2 & 7.0 & 1.4 & 7.2 & 0.5 & 5.5 & 1.6 & 2.9 & 2.9 & 0.7 & 2.5 & 48.6 \\
\hline PT & 0.4 & 0.1 & 1.1 & 3.1 & 0.4 & 1.8 & 1.2 & 4.6 & 0.2 & 0.7 & 0.4 & 0.6 & 0.2 & 14.7 \\
\hline RO & 4.7 & 0.0 & 4.5 & 2.1 & 0.2 & 2.3 & 0.7 & 0.4 & 0.8 & 1.6 & 1.0 & 1.6 & 0.5 & 20.5 \\
\hline SK & 6.8 & 0.3 & 0.8 & 1.2 & 0.0 & 0.5 & 0.2 & 1.6 & 0.8 & 0.8 & 0.1 & 0.1 & 0.5 & 13.7 \\
\hline SI & 0.4 & 0.3 & 0.5 & 0.5 & 0.1 & 0.3 & 0.1 & 0.6 & 0.1 & 0.5 & 0.2 & 0.1 & 0.3 & 3.9 \\
\hline ES & 7.6 & 1.4 & 9.4 & 8.6 & 2.0 & 9.4 & 1.3 & 6.8 & 1.9 & 3.4 & 1.6 & 5.3 & 4.2 & 62.9 \\
\hline SE & 4.5 & 0.5 & 1.9 & 0.7 & 0.7 & 1.5 & 0.1 & 13.4 & 0.8 & 1.5 & 1.8 & 0.4 & 9.7 & 37.3 \\
\hline GB & 11.8 & 1.2 & 9.2 & 6.7 & 0.0 & 10.6 & 2.9 & 6.0 & 4.0 & 7.1 & 0.0 & 2.6 & 31.4 & 93.5 \\
\hline EU28 & 148.5 & 26.5 & 154.0 & 86.9 & 11.4 & 114.4 & 17.9 & 114.9 & 32.1 & 75.8 & 28.1 & 28.9 & 78.1 & 917.6 \\
\hline
\end{tabular}


Table 3 Breakdown of Carnot waste heat potential divided by member state and industrial sector [TWh]

\begin{tabular}{|c|c|c|c|c|c|c|c|c|c|c|c|c|c|c|}
\hline & $I \& S$ & NFM & $C \& P$ & NMM & M\&Q & $\mathrm{F} \& \mathrm{~T}$ & $\mathrm{~T} \& \mathrm{~L}$ & PPP & $\mathrm{TE}$ & M & W\&WP & $\mathrm{C}$ & NS & Total \\
\hline $\mathrm{AU}$ & 2.7 & 0.4 & 0.6 & 1.0 & 0.2 & 0.7 & 0.1 & 1.6 & 0.1 & 0.6 & 0.4 & 0.6 & 0.2 & 9.2 \\
\hline $\mathrm{BE}$ & 2.5 & 0.4 & 3.1 & 1.8 & 0.0 & 1.7 & 0.2 & 0.5 & 0.2 & 0.3 & 0.1 & 0.2 & 0.6 & 11.8 \\
\hline BG & 0.1 & 0.2 & 0.5 & 0.7 & 0.1 & 0.3 & 0.1 & 0.2 & 0.0 & 0.1 & 0.0 & 0.1 & 0.1 & 2.4 \\
\hline CR & 0.0 & 0.0 & 0.1 & 0.4 & 0.0 & 0.3 & 0.0 & 0.1 & 0.0 & 0.1 & 0.0 & 0.1 & 0.0 & 1.3 \\
\hline CY & 0.0 & 0.0 & 0.0 & 0.2 & 0.0 & 0.0 & 0.0 & 0.0 & 0.0 & 0.0 & 0.0 & 0.0 & 0.0 & 0.2 \\
\hline $\mathrm{CZ}$ & 2.1 & 0.1 & 0.6 & 1.4 & 0.1 & 0.7 & 0.1 & 0.4 & 0.4 & 0.7 & 0.1 & 0.2 & 0.7 & 7.8 \\
\hline DK & 0.1 & 0.0 & 0.2 & 0.5 & 0.1 & 0.7 & 0.0 & 0.1 & 0.0 & 0.2 & 0.0 & 0.2 & 0.1 & 2.2 \\
\hline $\mathrm{EE}$ & 0.0 & 0.0 & 0.0 & 0.2 & 0.0 & 0.1 & 0.0 & 0.1 & 0.0 & 0.0 & 0.1 & 0.1 & 0.0 & 0.6 \\
\hline FI & 1.2 & 0.2 & 0.7 & 0.3 & 0.2 & 0.3 & 0.0 & 3.8 & 0.0 & 0.2 & 0.3 & 0.6 & 0.2 & 8.0 \\
\hline FR & 6.5 & 1.4 & 2.8 & 4.6 & 0.2 & 5.5 & 0.3 & 2.6 & 1.1 & 1.8 & 0.5 & 1.5 & 0.9 & 29.7 \\
\hline $\mathrm{DE}$ & 14.4 & 3.2 & 8.9 & 8.7 & 0.4 & 6.5 & 0.6 & 6.0 & 2.7 & 5.6 & 1.1 & 0.0 & 2.3 & 60.6 \\
\hline GR & 0.1 & 1.6 & 0.1 & 0.8 & 0.1 & 0.5 & 0.0 & 0.1 & 0.0 & 0.0 & 0.0 & 0.2 & 0.2 & 4.0 \\
\hline HU & 0.5 & 0.3 & 0.9 & 0.5 & 0.0 & 0.7 & 0.0 & 0.2 & 0.2 & 0.5 & 0.0 & 0.3 & 0.2 & 4.4 \\
\hline IE & 0.0 & 1.5 & 0.1 & 0.4 & 0.1 & 0.5 & 0.0 & 0.0 & 0.0 & 0.3 & 0.1 & 0.0 & 0.2 & 3.3 \\
\hline IT & 5.1 & 1.6 & 2.4 & 5.6 & 0.1 & 3.2 & 1.4 & 2.1 & 0.2 & 3.8 & 0.2 & 0.5 & 0.8 & 27.1 \\
\hline LV & 0.0 & 0.0 & 0.0 & 0.2 & 0.0 & 0.1 & 0.0 & 0.0 & 0.0 & 0.0 & 0.2 & 0.1 & 0.0 & 0.7 \\
\hline LT & 0.0 & 0.0 & 0.2 & 0.3 & 0.0 & 0.2 & 0.0 & 0.0 & 0.0 & 0.0 & 0.1 & 0.0 & 0.0 & 0.9 \\
\hline LU & 0.2 & 0.0 & 0.0 & 0.2 & 0.0 & 0.0 & 0.0 & 0.0 & 0.0 & 0.0 & 0.0 & 0.0 & 0.0 & 0.6 \\
\hline MT & 0.0 & 0.0 & 0.0 & 0.0 & 0.0 & 0.0 & 0.0 & 0.0 & 0.0 & 0.0 & 0.0 & 0.0 & 0.0 & 0.0 \\
\hline NL & 2.6 & 0.2 & 5.1 & 0.8 & 0.1 & 2.8 & 0.1 & 0.7 & 0.1 & 0.6 & 0.1 & 0.9 & 0.3 & 14.5 \\
\hline PL & 2.7 & 0.8 & 1.5 & 3.8 & 0.3 & 2.3 & 0.1 & 1.2 & 0.4 & 0.7 & 0.5 & 0.2 & 0.6 & 15.1 \\
\hline PT & 0.2 & 0.1 & 0.2 & 1.4 & 0.1 & 0.5 & 0.3 & 0.8 & 0.1 & 0.1 & 0.1 & 0.2 & 0.0 & 4.0 \\
\hline RO & 1.7 & 0.0 & 1.1 & 0.9 & 0.1 & 0.7 & 0.2 & 0.1 & 0.2 & 0.5 & 0.2 & 0.5 & 0.1 & 6.5 \\
\hline SK & 2.5 & 0.1 & 0.2 & 0.6 & 0.0 & 0.2 & 0.1 & 0.3 & 0.2 & 0.2 & 0.0 & 0.0 & 0.2 & 4.6 \\
\hline SI & 0.1 & 0.2 & 0.1 & 0.2 & 0.0 & 0.1 & 0.0 & 0.2 & 0.0 & 0.1 & 0.0 & 0.0 & 0.1 & 1.2 \\
\hline ES & 2.8 & 0.8 & 2.6 & 3.8 & 0.7 & 2.6 & 0.4 & 2.2 & 0.5 & 0.9 & 0.3 & 2.0 & 1.5 & 21.0 \\
\hline SE & 1.7 & 0.2 & 0.4 & 0.4 & 0.3 & 0.4 & 0.0 & 2.1 & 0.1 & 0.2 & 0.3 & 0.1 & 1.5 & 7.5 \\
\hline GB & 4.4 & 0.7 & 1.8 & 3.6 & 0.0 & 3.6 & 1.0 & 1.7 & 1.2 & 1.8 & 0.0 & 1.0 & 9.1 & 29.8 \\
\hline EU28 & 54.2 & 14.1 & 34.1 & 43.6 & 3.3 & 35.1 & 5.5 & 27.1 & 7.9 & 19.7 & 4.8 & 9.6 & 19.9 & 278.9 \\
\hline
\end{tabular}

\section{References}

Agathokleous R, Bianchi G, Panayiotou G et al (2019) Waste heat recovery in the EU industry and proposed new technologies. Energy Procedia 161:489-496. https://doi.org/10.1016/j.egypro. 2019.02.064

Brueckner S, Miró L, Cabeza LF et al (2014) Methods to estimate the industrial waste heat potential of regions-a categorization and literature review. Renew Sustain Energy Rev 38:164-171. https://doi.org/10.1016/J.RSER.2014.04.078

Elias CN, Stathopoulos VN (2019) A comprehensive review of recent advances in materials aspects of phase change materials in thermal energy storage. Energy Procedia 161:385-394. https:// doi.org/10.1016/J.EGYPRO.2019.02.101

European C (2016a) EU energy in figures: statistical pocket book

European C (2016b) Eurostat Database

EuroStat (2018) Primary Energy Consumption in EU

Forman C, Muritala IK, Pardemann R, Meyer B (2016) Estimating the global waste heat potential. Renew Sustain Energy Rev 57:1568-1579. https://doi.org/10.1016/J.RSER.2015.12.192
Hammond GP, Norman JB (2014) Heat recovery opportunities in UK industry. Appl Energy 116:387-397. https://doi.org/10.1016/j. apenergy.2013.11.008

International Energy Agency (2016) Key world energy statistics

IPCC (2007) Climate Change 2007: Mitigation. Contribution of Working Group III to the Fourth Assessment Report of the Intergovernmental Panel on Climate Change

Jouhara H, Khordehgah N, Almahmoud S et al (2018) Waste heat recovery technologies and applications. Therm Sci Eng Prog 6:268-289. https://doi.org/10.1016/J.TSEP.2018.04.017

Li Y-R, Du M-T, Wu C-M et al (2014) Potential of organic Rankine cycle using zeotropic mixtures as working fluids for waste heat recovery. Energy 77:509-519. https://doi.org/10.1016/J. ENERGY.2014.09.035

Liu B-T, Chien K-H, Wang C-C (2004) Effect of working fluids on organic Rankine cycle for waste heat recovery. Energy 29:1207-1217. https://doi.org/10.1016/J.ENERGY.2004.01.004

Markets (2018) Waste Heat Recovery System Market by Application (Preheating and Steam \& Electricity Generation), End-Use Industry (Petroleum Refining, Metal Production, Cement, Chemical, Paper \& Pulp, and Textile) - Global Trends \& Forecasts to 
2021. https://www.marketsandmarkets.com/Market-Reports/ waste-heat-recovery-system-market-202657867.html

Merienne R, Lynn J, McSweeney E, O’Shaughnessy SM (2019) Thermal cycling of thermoelectric generators: the effect of heating rate. Appl Energy 237:671-681. https://doi.org/10.1016/ J.APENERGY.2019.01.041

Miró L, Gasia J, Cabeza LF (2016) Thermal energy storage (TES) for industrial waste heat (IWH) recovery: a review. Appl Energy 179:284-301. https://doi.org/10.1016/J.APENERGY.2016.06. 147

Ommen T, Jensen JK, Markussen WB et al (2015) Technical and economic working domains of industrial heat pumps: part 1 Single stage vapour compression heat pumps. Int $\mathbf{J}$ Refrig 55:168-182. https://doi.org/10.1016/J.IJREFRIG.2015.02.012

Panayiotou GP, Bianchi G, Georgiou G et al (2017) Preliminary assessment of waste heat potential in major European industries. Energy Procedia 123:335-345. https://doi.org/10.1016/j.egypro. 2017.07.263

Papapetrou M, Kosmadakis G, Cipollina A et al (2018) Industrial waste heat: estimation of the technically available resource in the EU per industrial sector, temperature level and country. Appl Therm Eng 138:207-216. https://doi.org/10.1016/J.APPLTHER MALENG.2018.04.043
QYResearch G (2018) 2018-2025 waste heat recovery system market global key player, demand, growth, opportunities and analysis forecast

Roth H, Lucas K, Solfrian W, Rebstock F (1996) Die Nutzung

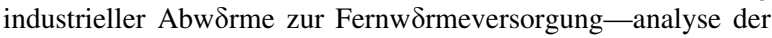
Hemmnisse fór die Nutzung industrieller Abworme zur Fernwormeversorgung

Simeone A, Luo Y, Woolley E et al (2016) A decision support system for waste heat recovery in manufacturing. CIRP Ann 65:21-24. https://doi.org/10.1016/J.CIRP.2016.04.034

Wei D, Lu X, Lu Z, Gu J (2007) Performance analysis and optimization of organic Rankine cycle (ORC) for waste heat recovery. Energy Convers Manag 48:1113-1119. https://doi.org/ 10.1016/J.ENCONMAN.2006.10.020

Woolley E, Luo Y, Simeone A (2018) Industrial waste heat recovery: a systematic approach. Sustain Energy Technol Assessments 29:50-59. https://doi.org/10.1016/J.SETA.2018.07.001

Yang Y, Wang S, He W (2019) Simulation study on regenerative thermoelectric generators for dynamic waste heat recovery. Energy Procedia 158:571-576. https://doi.org/10.1016/J.EGY PRO.2019.01.154 